\title{
Development Portable Spirometer using MPXV7002DP Sensor and TFT Display for Lung Disease Detection.
}

\author{
Lizarazu Maulidil Li Kharis", Andjar Pudji, Priyambada Cahya Nugraha \\ Department of Medical Electronics Engineering Technology, Poltekkes Kemenkes Surabaya \\ Jl. Pucang Jajar Timur No. 10, Surabaya, 60282, Indonesia \\ \#riokhariz@gmail.com, andjar.pudji@gmail.com,pcn1967@poltekkesdepkes-sby.ac.id
}

\begin{abstract}
Article Info
Article History:

Received May 15, 2020

Revised Nov 14, 2020

Accepted Nov 25, 2020

Abstract

Chronic obstructive pulmonary disease (COPD) is a disease whose prevalence tends to increase annually, with the World Health Organization (WHO) data predicting in 2020 the disease is the cause of the third-highest mortality worldwide. The assessment of the recurrence of COPD patients is very important, as it will accelerate the decline of lung function and health status. The purpose of this research is to design a spirometer by utilizing the MPXV7002DP sensor and equipped with a graphical display as well as lung health status on the Nextion TFT LCD. A portable Spirometer design has been done using the MPXV7002DP pressure sensor out as a transducer with a display on the Nextion TFT LCD. The design aims to determine the health

Keywords:

Lung Volume;

Arduino;

MPXV7002DP Sensor;

Spirometer; of lung function by knowing the volume of lung Forced Vital Capacity (FVC), Forced Expired Volume in one second (FEV1), and Vital Capacity (VC). The working principle of this tool is to process the pressure from the results of the user blowing to the sensor through a mouthpiece which is designed based on Venturimeter law, the data will be processed by the Arduino microcontroller 2560 to be displayed on the LCD TFT and Nextion stored in SD card memory. The result of module validation data against a Spirometer $3 \mathrm{~L}$ calibrator Benchmarking tool was obtained $1.58 \%$ VC error. The value is still below the $5 \%$ error tolerance limit so that the VC parameters in the secure module is used.
\end{abstract}

\author{
Corresponding Author : \\ Andjar Pudji \\ Department of Medical Electronics Engineering Technology \\ Politeknik Kesehatan Kementerian Kesehatan Surabaya \\ J1. Pucang Jajar Timur No. 10, Surabaya (60282), Indonesia \\ Email : andjar.pudji@gmail.com
}

This work is an open access article and licensed under a Creative Commons Attribution-ShareAlike 4.0 International License (CC BY-SA 4.0).

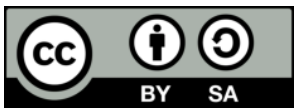

\section{INTRODUCTION}

Chronic obstructive pulmonary disease (COPD) is a disease whose prevalence tends to increase annually, with the World Health Organization (WHO) data predicting in 2020 the disease is the cause of the third-highest mortality worldwide. The assessment of the recurrence of COPD patients is very important, as it will accelerate the decline of lung function and health status. The purpose of this research is to design a spirometer by utilizing the MPXV7002DP sensor and equipped with a graphical display as well as lung health Chronic OBSTRUCTF Lung disease (COPD) is a disease whose prevalence tends to increase by the year. The World Health Organization (WHO) estimates that in 2020, the disease is the cause of third-time mortality worldwide[1]. Indonesian ranks sixth (6) in the order of the mortality rate and defect of the PPOK based on WHO's estimate in 2010, with a total of 58,4/100,000 inhabitants and a disability-adjusted life years (DALYs) Figure 
of $613 / 100,000$ inhabitants[2]. Chronic obstructive pulmonary disease itself is a health disorder characterized by obstruction in a sedentary and developing airway, due to the increased chronic inflammatory response of the airway and lungs against particles or harmful gases[3]. The assessment of the recurrence of COPD patients is very important, as it will accelerate the decline of lung function and health status[4]. Lung function is also influenced by the process of lung ventilation (air swap between the outside air and the lung alveoli), the diffusion process in alveoli and good blood circulation. Good lung ventilation is influenced by many factors, such as the magnitude of static and dynamic lung volumes. The normal value for each volume and capacity of the lungs varies and is influenced by age, height, to-lamin, ethnicity, weight, and body shape[5]. By measuring the volume of the lungs can be known lung ability to expand, and the presence or absence of pulmonary abnormalities (obstruction and restriction). One of the medical instruments used to diagnose lung disease is the, often referred to as spirometer. This spirometer is a measurement of the volume and airflow that can be exhaled from the lungs. Spirometer is a tool that serves to measure how much air it can breathe (inspiration) and Exhale (expiratory) by someone in a certain duration so that the results can provide information about the health of the lungs[6]. Spirometry can also measure an expiratory flow i.e. the forced expiratory volume of the first second (VEP1/FEV1) and forced vital capacity $(\mathrm{KVP} / \mathrm{FVC})$. Interpretation of spirometry results are described by values VEP1/FEV1, KV/VC, APE, and VEP1/KVP. Abnormal values can depict basic abnormalities of pulmonary function, namely obstruction, restriction and combination[7].

In 2013 it has been created a health instrumentation that has the same function as the spirometer. The way used in this system is to measure the volume of breathing air that is exhaled by the patient (an expiratory) using the MPX5100DP pressure sensor. The results of this test are the volume of air-filtration displayed in the form of graphs and numbers. The highest Test error value is $18.24 \%$. While the average error value of the overall testing of the appliance is $7.3 \%$ [8] The system can function normally but the \%error value in this tool is still high so it is not worth to use. In 2017, Kemalasari also successful to realize a portable non-invasive spirometer by using a piezoelectric sensor from the development of previous tools that he had made. The measurement result will be displayed on the LCD of the chart and the data of the measurement results will be stored on the SD card so that the measurement result data can be processed and analyzed further on the PC. On the LCD of the chart will appear the output signal in the form of a vital capacity of lung signals. From these signals will be known values of vital lung capacity (VC) along with the status of lung health and respiration rate per minute (RPM)[9]. However, this system has not been accompanied by an indicator so it requires an action to do the diagnosis. In 2018 it has been successfully made "Design of the Portable Spirometer-based Arduino Uno" by the Akbar Novel which uses the water pressure sensor MPX5500DP as its transducer which then data from the pressure sensor will be processed by the microcontroller and displayed on the LCD in the form of 3 parameters of lung function examination, namely
VC (Vital Capacity), FVC (Forced Vital Capacity), FEV1 (Forced Expiratory Volume1). In this tool created the result of reading 3 parameters will be compared with the standard tool or compared to its value with Calibration Syringe. This study selected the air pressure sensor using the Silicon Stress-Strain gauge type MPX5500DP. The tool can work well, but the display does not display disease indicators in the lungs so it requires an action again to perform the diagnosis. In the suggestion also said that the sensor is needed better and responsive so that the volume measurements of the lungs become more accurate. In the year 2019 was also successfully made "Design of the Portable Spirometer based Arduino ATMega328 for the calculation of FEV1 and FEV" by Lia Andriani from Poltekkes Kemenkes Surabaya. The method used is the measurement FEV1 and FVC using the pressure sensor MPX5100DP with a lung health indicator that is Restruktif, obstructive, as well as the normal state through the LCD of the character and the measurement is stored in the micro SD so that the data can be compared between before and after the therapy. The tools that have been created have an error value of $0.97 \%$ for FVC, 3.83\% for FEV1, and $2.50 \%$ in the FEV1/FVC ratio. This journal is also accompanied by a suggestion that mouthpiece turnover is felt to affect the size of the measurement error[10].

By looking at the conditions and shortcomings above, among others: 1.) \%Error is quite high. 2.) There are no indicators. 3.) The need for sensor replacement and mouthpiece design. 4.) The module design is less futuristic, then the author will make "PORTABLE SPIROMETER WITH TFT LCD DISPLAY (FVC, FEV1, and VC)". In this research conducted the development of spirometer tools from several previous tools is portable by replacing the sensor MPX5500DP with another MPXV7002DP in the hopes of getting more accurate results and review the error value. The measurement results will be displayed on the TFT LCD. On display is the chart on TFT LCD in addition to the purpose of more innovative tools also aims to observe the diagnosis can be easier with the monitoring of the is graph changes. On TFT LCD, in addition to the displayed percentage value of volume measurement and pulmonary capacity include FEV1, FVC, and VC also displayed indicators of Restruktif and obstructive disease automatically.

The paper is consists of chapter I of the Introduction, chapter II which contains the materials and methods, the result in chapter III, Chapter IV which contains the discussion, and chapter $\mathrm{V}$ which contains the conclusion.

\section{MATERIALS AND METHODS}

\section{A. Experimental Setup}

In this study used 5-10 subjects with age criteria above 20 years and high between 150 to $172 \mathrm{~cm}$. Subjects were taken randomly according to required parameters and the collected data was repeated 3 times if needed.

\section{1) Materials and Tool}

The study used a disposable mouthpiece with a $3 \mathrm{D}$ tube that was built on the principle of low venturimeter. The 
mouthpiece is positioned in the mouth and the air pressure of the Mouthpiece will go into the circuit pressure sensor MPXV7002DP by NXP Product. The Arduino ATmega $2560 \mathrm{R} 3$ microcontroller is used to process the data generated from the sensor and then the voltage data will be converted into a volume unit using the 1.8 .9 version of Arduino application. The measurement results are displayed on Nextion TFT LCD with NX4024K032 series and 3.2 inches in size, using Nextion Editor app version 0.58 . Micro-SD SD card memory is used to store volume measurement data. Standard Spirometer brand CardinalHealth is used to compare the value of the module with the size of 3 liters Spirometer brand Hans Rudolph. Inc. With 5530 Series as its medium.

2) Experiment

In this study, once the module design is complete, the module will be tested with a well-search spirometer.

\section{B. The Block Diagram}

In this study, the measurement of the pulmonary volume was performed based on the mouth blowing of the respondent in the mouthpiece connected with the MPXV7002DP pressure sensor. The default analog to digital converter (A/D) on the Arduino Mega 2560 is used to convert analog data to digital, then the digital data will be converted to a unit of volume by using the Venturimeter principle. The results of volume measurement data are displayed on the Nextion TFT LCD with an indicator of the health status of the lungs and stored on the SD card.

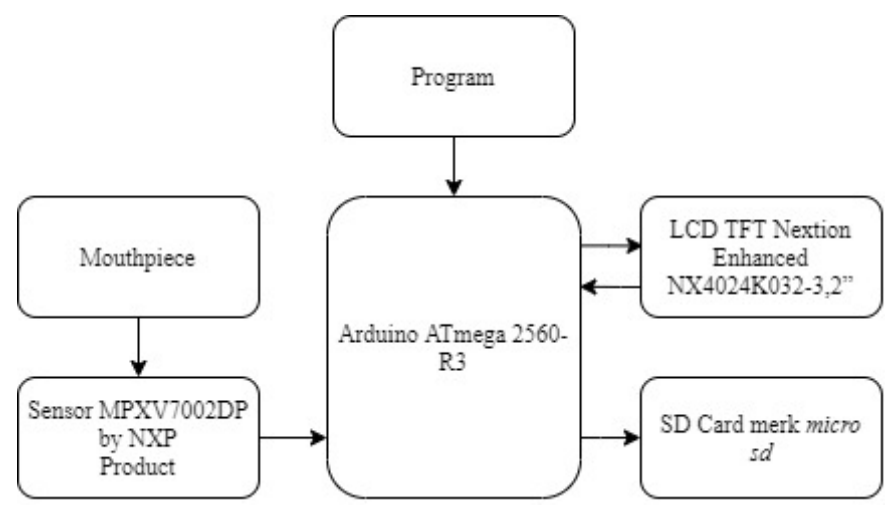

Fig. 1. The Block Diagram

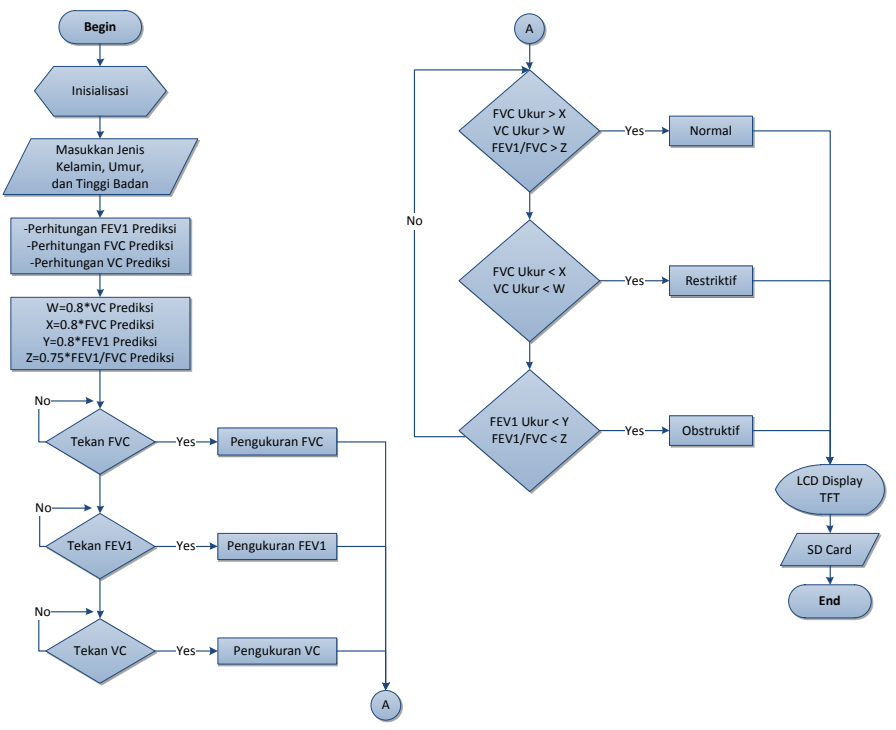

Fig. 2. The Flowchart of the Arduino Program

\section{The Flowchart}

The groove on the Arduino Program is created as shown in the Figure 2. After initializing the Arduino, the program will redirect on the charging of personal data including height, gender, and age. Then the program will calculate the predicted value to determine the health status of the lungs. Then the result will be saved on the SD Card.

\section{Nextion Connection}

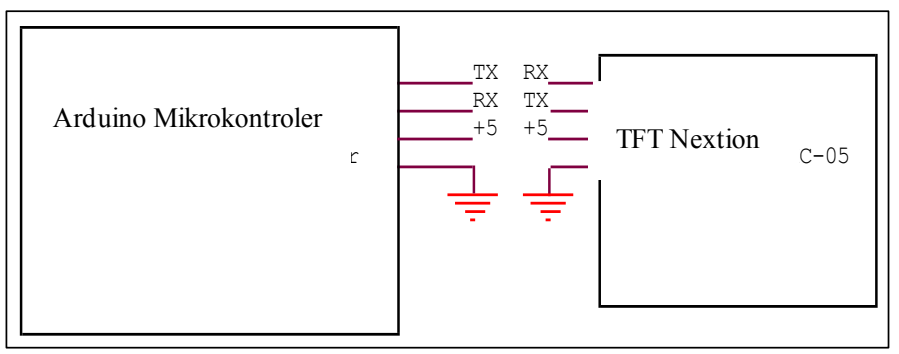

Fig. 3. TFT Nextion Conection

In Figure 3 It shows a configuration scheme of Nextion TFT LCD that is connected to the Arduino Mega microcontroller 2560. The Arduino TX pin is connected to a TFT LCD RX pin, while the Arduino RX Pin is connected to the LCD TFT TX pin. Next for source $+5 \mathrm{v}$ is connected with $+5 \mathrm{~V}$ as well as the ground source TFT LCD connected with the Arduino Mega ground 2560 which has been connected with the battery.

\section{RESULTS}

In this study, One parameter in the module was tested by comparing the module's measurement value using the mostsearch Spirometer tool. Module testing was conducted using the 3L calibrator media for Hans Rudolph. Inc. The results show that 1 such parameter is Vital Capacity (VC) in the module is feasible to use. 


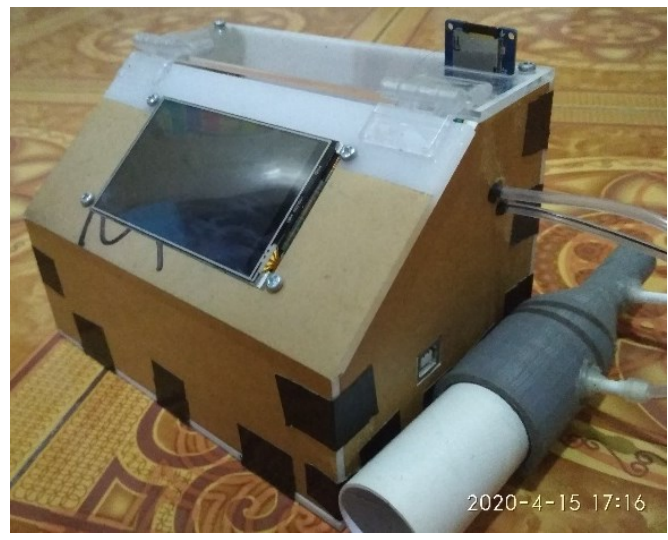

Fig. 4. Spirometer Module

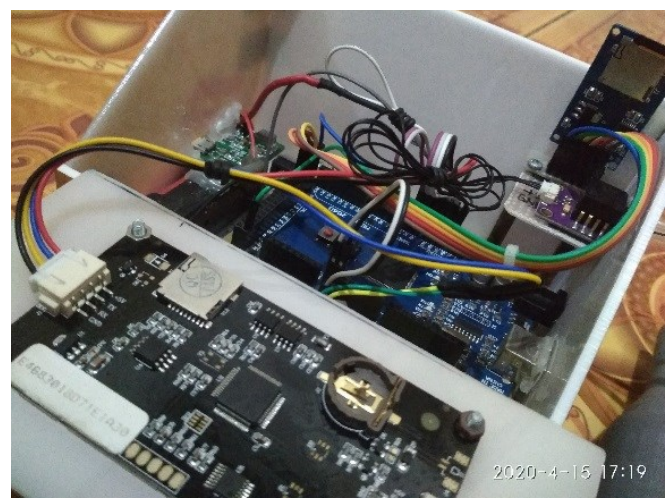

Fig. 5. Results of Microcontroller Circuit Design

\section{1) Spirometer Module Design}

The design of the tool can be seen in Figure 4. There is a disposable mouthpiece with 3D tubes created based on the principle of the Venturimeter and SD Card Module. Jack Arduino is available when programming is required, and there is a USB type B socket on the other side to recharge the battery. For the setting button and the screen is on the touchscreen LCD with the microcontroller circuit seen in Figure 5.

\section{2) Test-point measurement result}

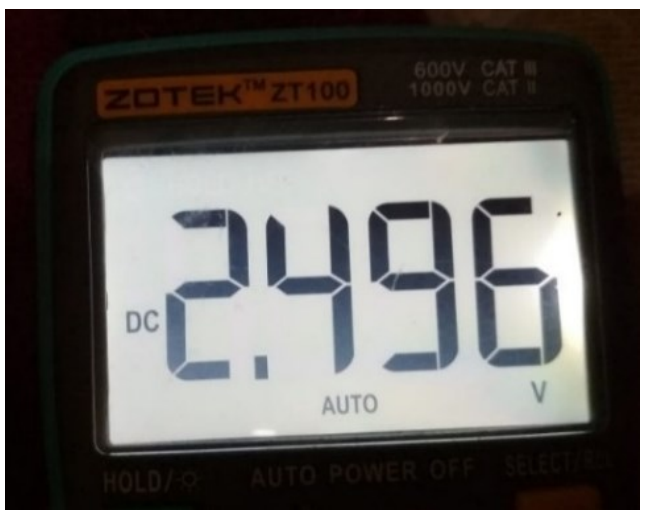

Fig. 6. MPXV7002DP Sensor output result before the patient breathes
Figure 6 shows the sensor output when measuring the patient's breathing volume before breathing the patient. The sensor output voltage Before breathing is $2.496 \mathrm{~V}$.

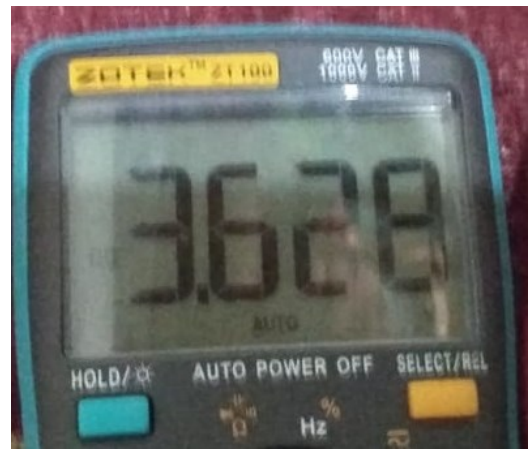

Fig. 7. MPXV7002DP Sensor output result after the patient breathes

Figure 7 shows the sensor output when measuring the patient's breathing volume after patient breathing. The sensor output voltage after breathing is $3.628 \mathrm{~V}$.

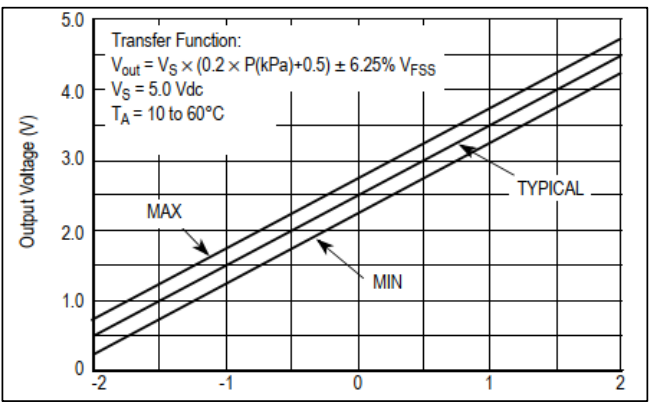

Fig. 8. Output versus Pressure Differential

Figure 8 shows the MPXV7002DP sensor output of a voltage when given pressure to the sensor.

3) The Listing Program for calculating FVC, FEV1, and VC In this paper, the software used Arduino version 1.8.9 for measurement programming FVC, FEV1, and VC. Nextion Editor version 0.58 to set the system on the Nextion TFT LCD. Program listings for Arduino are displayed in the Program Listing 1.

List of programs 1.

Program for calculating the value of FVC, FEV1, and VC.

void sensing() \{

if (page $==3)\{$

float voltage $=$ analogRead(pinSensor $) *(5.00 / 1023)$;

float $\mathrm{kpa}=($ voltage -2.5$) * 1000$;

float $\mathrm{v}=(((2 *(\mathrm{kpa} * 0.0001)) /$ airDensity $) /((\mathrm{sq}$ (Area1 /

Area2)) - 1));

float akar $=\operatorname{sqrt}(\mathrm{v})$;

float $\mathrm{q}=($ Area $1 *$ akar $) * 1000$;

$f v c=((q-3442)-66.24)-127$

if $(\mathrm{fvc}<=0)$ fvc $=0$; 


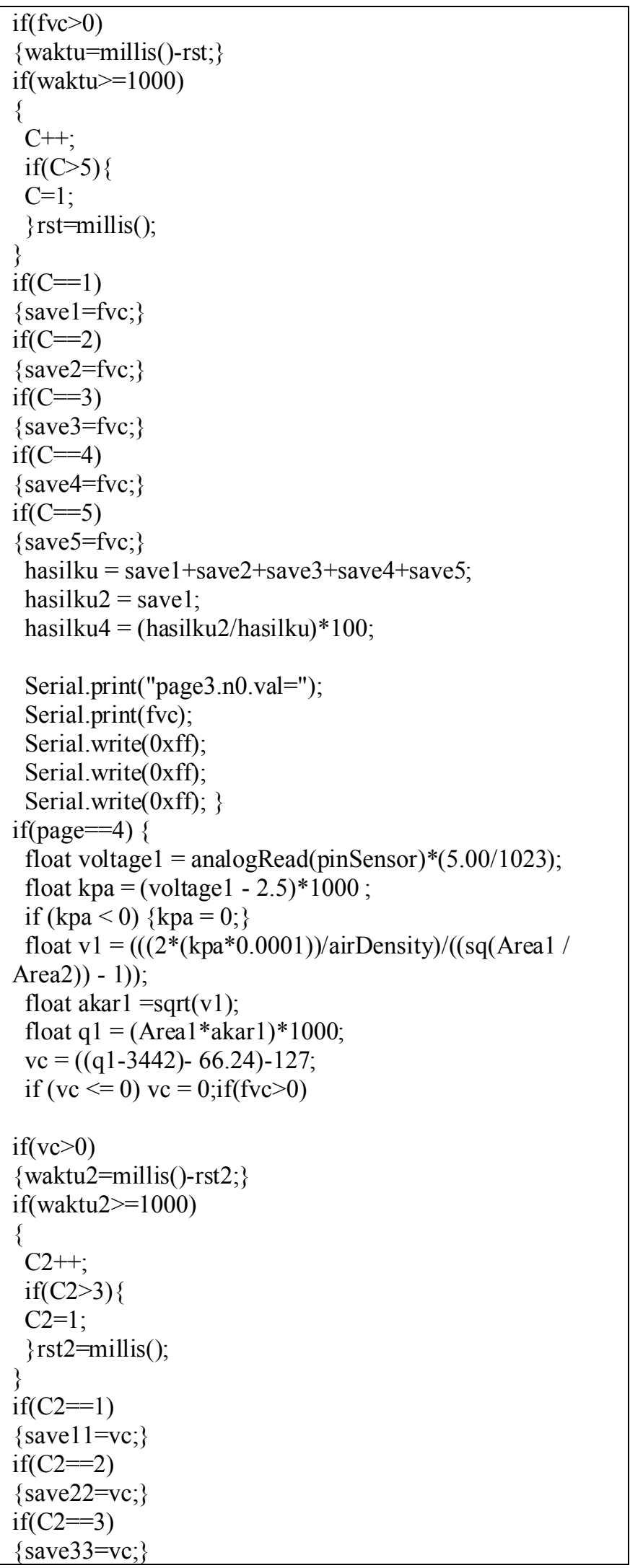

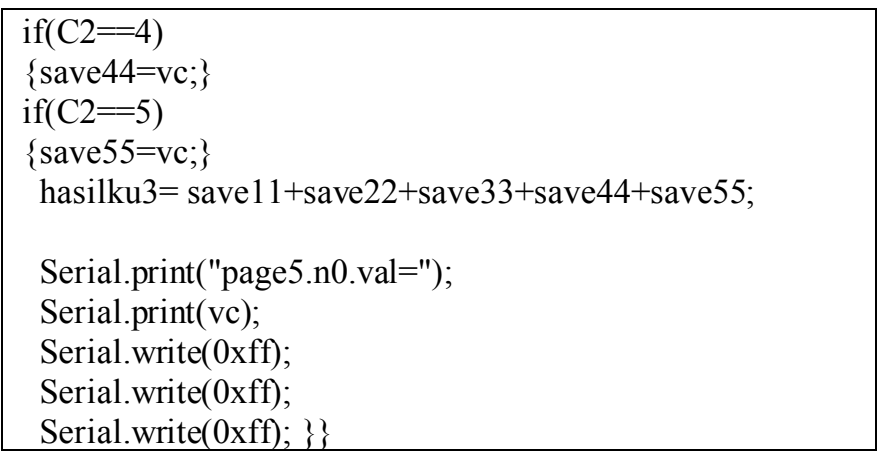

4) Storage of FVC, FEV1, ratio FFEV1/FVC, and VC Measurements to SD Card Memory

For the spirometer to store the results of the diagnosis such as age, height, gender, lung health status as well as the measurement results, then designed a storage program on the SD Card with the buttons available on the TFT LCD screen. Storage is needed to facilitate the monitoring process when a subsequent check is needed. The Listing Program is displayed as Program Listing 2.

List of programs 2 .

Program to store the results of FVC, FEV1, FEV1/FVC ratios, and $\mathrm{VC}$ measurements.

void savesd ()

\{

Serial.println("Sukses baca kartu microSD!");

myFile = SD.open("test2.txt", FILE_WRITE);

if (myFile)

myFile.println();

myFile.print $("======")$;

myFile.println();

myFile.print("ID = ");

myFile.println(id);

myFile.print("Jenis Kelamin= ");

if(gender) myFile.println("Laki-Laki");

else if(!gender) myFile.println("Perempuan");

myFile.print("Umur=");

myFile.print(umur);

myFile.print(" tahun");

myFile.println();

myFile.print("Tinggi=");

myFile.print(tinggi);

myFile.print(" cm");

myFile.println();

myFile.print("FEV1=");

myFile.print(hasilku2);

myFile.print(" Liter");

myFile.print(" / "); 
myFile.print(fev1x);

myFile.print(" Liter");

myFile.println();

myFile.print("VC=");

myFile.print(hasilku3);

myFile.print(" Liter");

myFile.print(" / ");

myFile.print(vcx);

myFile.print(" Liter");

myFile.println () ;

myFile.print("Rasio=");

myFile.print(rasio1);

myFile.print(" / ");

myFile.print(rasio2);

myFile.println();

myFile.print("Kondisi=");

myFile.print(ket);

myFile.println();

myFile.close();

Serial.println("SELESAI!");

\}

else \{

Serial.println("GAGAL TULIS coba.txt"); \}\}

5) Analysis and Measurement Results

TABLE I. TABLE OF FVC, FEV1, AND VC VOLUME MEASUREMENT

\begin{tabular}{|c|c|c|c|c|}
\hline \multirow[t]{2}{*}{ Data } & \multicolumn{4}{|c|}{ Alat Spirometer } \\
\hline & $\mathrm{VC}$ & $\mathrm{FVC}$ & FEV1 & FEV1/FVC \\
\hline 1. & $3,08 \mathrm{~L}$ & $2,82 \mathrm{~L}$ & $2,82 \mathrm{~L}$ & $100 \%$ \\
\hline 2. & $3,08 \mathrm{~L}$ & $2,74 \mathrm{~L}$ & $2,74 \mathrm{~L}$ & $100 \%$ \\
\hline 3. & $3,21 \mathrm{~L}$ & $2,78 \mathrm{~L}$ & $2,78 \mathrm{~L}$ & $100 \%$ \\
\hline 4. & $3,14 \mathrm{~L}$ & $2,89 \mathrm{~L}$ & $2,89 \mathrm{~L}$ & $100 \%$ \\
\hline 5. & $3,13 \mathrm{~L}$ & $2,81 \mathrm{~L}$ & $2,81 \mathrm{~L}$ & $100 \%$ \\
\hline 6. & $3,17 \mathrm{~L}$ & $2,81 \mathrm{~L}$ & $2,81 \mathrm{~L}$ & $100 \%$ \\
\hline 7. & $3,16 \mathrm{~L}$ & $2,89 \mathrm{~L}$ & $2,89 \mathrm{~L}$ & $100 \%$ \\
\hline 8. & $3,16 \mathrm{~L}$ & $2,86 \mathrm{~L}$ & $2,86 \mathrm{~L}$ & $100 \%$ \\
\hline 9. & $3,23 \mathrm{~L}$ & $2,89 \mathrm{~L}$ & $2,89 \mathrm{~L}$ & $100 \%$ \\
\hline 10. & $3,23 \mathrm{~L}$ & $2,77 \mathrm{~L}$ & $2,77 \mathrm{~L}$ & $100 \%$ \\
\hline Average & $3,16 \mathrm{~L}$ & $2,83 \mathrm{~L}$ & $2,83 \mathrm{~L}$ & $100 \%$ \\
\hline \multirow[t]{2}{*}{ Data } & \multicolumn{4}{|c|}{ Modul Spirometer } \\
\hline & $\mathrm{VC}$ & & & \\
\hline 1. & $2,97 \mathrm{~L}$ & & & \\
\hline 2. & $2,8 \mathrm{~L}$ & & & \\
\hline 3. & $3,38 \mathrm{~L}$ & & & \\
\hline
\end{tabular}

\begin{tabular}{cc}
\hline 4. & $3,31 \mathrm{~L}$ \\
\hline 5. & $3,01 \mathrm{~L}$ \\
\hline 6. & $3,18 \mathrm{~L}$ \\
\hline 7. & $3,25 \mathrm{~L}$ \\
\hline 8. & $3,18 \mathrm{~L}$ \\
\hline 9. & $3,11 \mathrm{~L}$ \\
\hline 10. & $2,94 \mathrm{~L}$ \\
\hline Average & $3,11 \mathrm{~L}$ \\
\hline$\%$ Error & $1,58 \%$ \\
\hline
\end{tabular}

The method used is to compare the pressure value (KPA) converted to the $\mathrm{mmHg}$ unit of the sensor with a DPM as well as comparing the value of modules with standard tools using a 3-Liter spirometer calibrator as it's medium.

Based on the VC measurements by using the MPXV7002DP sensor compared to the standard spirometer device with a 3-Liter spirometer Kalibrator Media on table 1 indicates that the maximum error value of $\mathrm{VC}$ is $1.58 \%$ with a measurement average of 3.11 liters.

From the difference in volume value in Table 1 , it can be caused by several factors, namely each technique of use calibrator against standard tools and Spirometer module does not necessarily produce the same pressure. Moreover, the rapid or slow use of a calibrator also affects the large and small pressures produced. The mouthpiece design also greatly affects the measurement results because the size of the mouthpiece is used in the Venturimeter principle formula. Therefore it takes several times the sample/test measurement to overcome it.

\section{Discussion}

In this research can be known that: has been made Portable Spirometer with TFT LCD (FVC, FEV1, and VC). The MPXV7002DP sensor test can be done by comparing the pressure result (KPA) converted to $\mathrm{mmHg}$ with the DPM tool. The microcontroller family can be used to process analog data from sensors to then convert to pressure and then convert to volume using the venturimeter principle and can set up a TFT LCD work system with the storage button on the SD Card. In previous research in 2017 using a piezoelectric sensor placed on the chest was obtained Error on VC parameters (Vital Capacity) with a success rate of $97.67 \%$, with this Error is known by $2.33 \%$ and in another study in 2019 using a different sensor that is MPX5100DP has obtained the largest Error value of $3.83 \%$. In this study only the VC parameters have been validated with an Error of $1.58 \%$. Thus the Error value of this VC parameter is smaller than previous research and the Error value is still below the 5\% error tolerance limit, therefore the error is still considered safe.

\section{CONClusion}

In this research can be developed/repaired shortcomings by improving the display of TFT LCD display to be more 
attractive. Using sensors other than MPXV7002DP that have high sensitivity and flow rate $(\mathrm{L} / \mathrm{s})$ so that the measurement results can be better. For example, using a Turbine Flowmeter sensor. Improve the mouthpiece design and create a system that is directly configured with PC (Personal Computer), Web, or Android to facilitate analysis and data transfer.

\section{REFERENCES}

[1] A. P. Pillai, A. M. Turner, and R. A. Stockley, "Global initiative for chronic obstructive lung disease 2011 symptom/risk assessment in $\alpha 1$-antitrypsin deficiency," Chest, vol. 144, no. 4, pp. 1152-1162, 2013.

[2] F. L. Kiechle, "Clinical pathology and revenue," $J$. Clin. Ligand Assay, vol. 29, no. 4, pp. 204-205, 2007.

[3] J. Vestbo et al., "Global strategy for the diagnosis, management, and prevention of chronic obstructive pulmonary disease GOLD executive summary," Am. J. Respir. Crit. Care Med., vol. 187, no. 4, pp. 347-365, 2013.

[4] A. Ban, A. Ismail, R. Harun, A. Abdul Rahman, S. Sulung, and A. Syed Mohamed, "Impact of clinical pathway on clinical outcomes in the management of COPD exacerbation," BMC Pulm. Med., vol. 12, 2012.

[5] E. A. Fachrial Harahap, "Uji Fungsi Paru," 2012.

[6] A. Bakhtiar, "Faal Paru Dinamis," J. Respirasi, vol. 3, no. 3, pp. 89-96, 2017.

[7] M. R. Miller et al., "Standardisation of spirometry," Eur. Respir. J., vol. 26, no. 2, pp. 319-338, 2005.

[8] A. Iqlimah, "Publikasi Jurnal Skripsi," Peranc. Alat Ukur Vol. Udar. Pernapasan Mns., 2013.

[9] K. KEMALASARI, P. S. WARDANA, and R. ADIL, "Spirometer Non-Invasive dengan Sensor Piezoelektrik untuk Deteksi Kesehatan Paru-Paru," J. Elkomika, vol. 5, no. 2, pp. 188-206, 2017.

[10] L. Andriani, I. Priyambada, C. Nugraha, and S. Lutfiah, "Portable Spirometer for Measuring Lung Function Health ( FVC and FEV1 )," vol. 1, no. 1, pp. 1-6, 2019. 